\title{
Use of Social Media Platforms in Promoting the Academic Library Services of City College of Angeles among Students
}

\author{
Hazelle Ann Yalung, Diana L. Tuliao, Princess Rona M. Gabriel, Solomon Ayodele Oluyinka, Mark Gil \\ Superio, and Richard Daenos
}

\begin{abstract}
Social media has great impact of its use by college libraries; thus, the academic library of a city college in the Philippines has been considered in this study. SmartPLs was employed to predict the use of social media platforms in promoting the academic library services of the college. Descriptive method was used, and validated structured questionnaires were distributed to 174 student-respondents. Majority use their own social media accounts. They have an access to the academic library which has three main social media platforms: Facebook, Twitter, and Instagram. The factors they consider are purpose, library account contents, and relative advantages of social media. Findings revealed that these factors influence the promotion of academic library services through social media platforms. Active usage of library social media accounts should be encouraged to provide better promotion of the library, particularly its resources and services.
\end{abstract}

Index Terms-Academic library services, Philippines, social media platforms, students.

\section{INTRODUCTION}

Libraries in today's technological age are embracing the use of social networking sites in reaching out to its library users. It is a cost-effective way of strengthening the quality of the services of the library [1] Social networking services can be explored to meet the library users' expectations, which provides better services in acquiring information and requirements needed [2].

In this millennium era, libraries have become more modern in their services, thus providing exceptional and unique library promotional efforts and quality services for their millennial users. Social media provides library information services for effective promotions [3]; with the proliferation of various technological advancement, the use of social media has become an effective method for social relations and interactions; people use it as a way of communicating and interacting with each other [4]. Social media sites such as LinkedIn, Facebook, Twitter, and Blogs are popular within school communities. They help students to further interact, communicate, and share ideas world-wide [5]. These media serve as technological aids in spreading and disseminating

Manuscript received November 12, 2019; revised March 31, 2020.

Hazelle Ann Yalung, Diana L. Tuliao, Princess Rona M. Gabriel, Mark Gil Superio, and Richard Daenos are with Institute of Computing Studies and Library Information Science, City College of Angeles, Philippines.

Solomon Ayodele Oluyinka is with College of Business Administration and Accountancy, Baliuag University, Bulacan, Philippines (the corresponding author; e-mail: solomon467@gmail.com). information about the library resources, specifically its vast collection of books, as well as the facilities and services offered [6].

Chu [7] mentioned that most of the students usually use social media as a tool for interaction between groups of people to engage connection. With the positive contributions of the social networking sites, students from various universities are expected to be properly educated and guided on the responsible use of social media. Social media is perceived as an interactive technology to acquire information needed by the users [8]. Library users can easily use and access instant and fast information because of the updated application of social media tools [9].

City College of Angeles (CCA) was established since 2012 located in Angeles City, Pampanga, Philippines with a population of more than two thousand students and with one academic library allowing the use of social media platforms like Facebook, Twitter, and Instagram for academic purposes. The academic library assured that these media establish communication and collaboration among students. Thus, the aim of this study is to identify the use of social media platforms in promoting the academic library services among students. Specifically, it determined the current social media platforms used by students. It further described the purpose and relative advantage of social media usage and the specific library content which students most frequently visited.

\section{LITERATURE REVIEW}

Social media could be defined as internet-based application that enables users to make and share information among social groups [10]. The use of social media in libraries is not a great step for outside library walls but it is just another way of doing what has already been done. Social media tools can be used for the entire library as a means of enhancing communication and presentation. Eze [11] stated that with the use of social media platforms, the library makes its services more engaging with the students without allotting a huge budget; thus, it is an advantage for the librarians. With the use of social media platforms, participation and interaction with the community becomes more active, and dissemination of information becomes more dynamic when users read posted messages.

Further, social networking sites are used to announce library events such as gaming nights. They inform users about new resources added to library collections, aside from giving links to articles, videos, or internet information that 
are related and useful to the users. Social media also exploit a significant function in developing relationships with the community by letting users ask questions or provide feedback about library services [9]. Mahmood [12] stressed in his study the result of recognizing new transformations of the library in using social networking sites. In addition, Shafawi [6] stated that social media sites are considered as the easiest way to update library outreach programs and exhibitions; they can be used as online customer services and interactive feedback platform like the use of Facebook, Twitter, Myspace, Blogs, Widgets, YouTube, Flickr, and Instagram to name a few. Social media has become an effective information dissemination tool which requires minimal effort that can be utilized by libraries for marketing informational resources and cultural efforts.

Miyanda [13] found out that social networking sites have caused libraries to have an open door in reaching out to clients. His research findings indicated that students supported the connection of social networking sites to the library's web page to improve collaboration between the community of libraries and universities.

Chu [7] presented a study related to the purpose of social networking tools in academic libraries. Results showed that twenty-seven libraries $(71.1 \%)$ used social networking tools, five $(13.1 \%)$ were potential users, and six $(15.8 \%)$ did not plan to use them at all. Facebook and Twitter were the most commonly adopted tools in university libraries. The study examined the applications of Web 2.0 technologies and social media tools to "bring" the academic library to its students and its implications. Academic libraries must foster ways to reach out among users of relevant social media sites [14]. The study of Jones [10] marketed the social media services provided to young generations, thus encouraging many libraries to open accounts on social media platforms.

Social media has a great impact on its use by libraries as well as information organizations. It is an advantage tool that can be used in reaching out to library users and extending services through other libraries and social network sites. The application of social media is spreading day by day globally which allows users to acquire relevant information that would serve as an effective promotional means for academic libraries.

Further, Howard [15] revealed in a study that students currently use Facebook, YouTube, and Snapchat more than other social media types. Responses showed that respondents preferred to acquire information using social media platforms such as Facebook, Instagram, and Twitter. Other findings showed that students were very much interested in all types of content from the libraries on Facebook, Twitter, and Instagram, but not interested in receiving business news or information related to library resources on Snapchat.

Palmer [16] found out that other university libraries used Facebook and Twitter accounts. The data were gathered in the direct messages and shared tweets from the libraries. The user of the Twitter and Facebook revealed that he has single and multiple accounts to widely share the information about the library posts and links to know the library activities, services, and to interact with one another. Most academicians were able to construct different ideas, including new designs in interacting with the others using social media platforms
[17].

Social media has so many benefits such that Facebook is commonly known to interact with users, sharing about library events or news, sharing photos, and also marketing library services. Internet is one of the most important necessities of students nowadays, especially in terms of sharing huge information and to communicate with each other. Libraries are now using social media platforms to provide services among students. A related research as well determined the effectiveness of Facebook and twitter applications in promoting library services. The results showed that Facebook gave the best impacts as promotional tools in spreading the content of information. They are channels in answering users' inquiries and in providing immediate feedbacks on promotional initiatives [8]. Burrio [18] also mentioned that the benefits of social media as a solid network tool include creating a bond among professionals for disseminating data.

Bakare [19] conducted a study related to identifying the use of social media platforms to promote library services and profitable librarianship. The findings revealed that social media platforms facilitated two-way communication and ease of communication among library users. Furthermore, it provided a forum for feedbacks, increased the number of library users, and benefitted librarians from experiencing traffic which is generated as users visit their blog pages.

A study was conducted on how social media has become the most widely used tool for communication. Results revealed that Facebook is the most useful social networking site based on the respondents' answers [16]. Elkaseh [20] in his study also justified that purpose of using a particular technology may influence adoption.

With the aforementioned significance of social media, the following factors determine the use of social media in promoting the library services of City College of Angeles among its students (see Fig. 1).

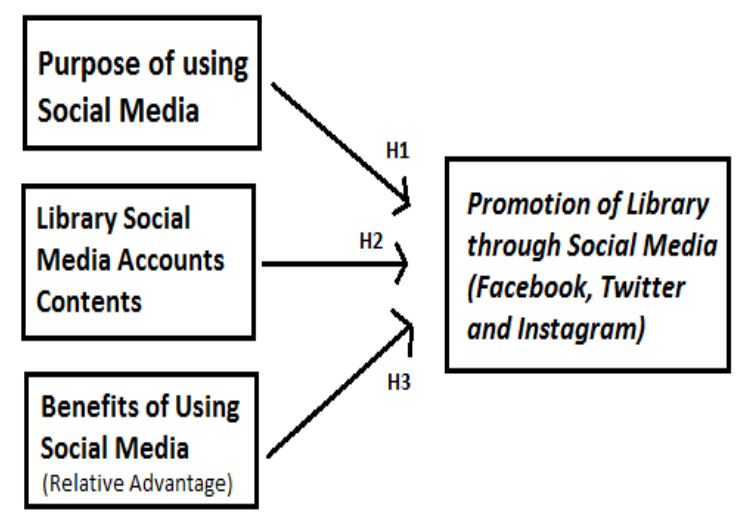

Fig. 1. The paradigm of the study.

Thus, the hypotheses of the study include the following:

The study of Elkaseh [20] justified that purpose of using a particular technology may influence adoption. Similarly, aforementioned in the previous section of this study Chu [7] study also affirmed that purpose of social networking tools in academic libraries cannot be ignored. Thus, hypothesized that purpose of using social media platforms has significant influence towards the promotion of academic library among students (H1);

The findings in the study of Howard [15] showed that 
students were interested in all types of content from the libraries on Facebook, Twitter, and Instagram, but not interested in receiving business news or information related to library resources on Snapchat. Also, the study of Palmer [16] found out that other university libraries used Facebook and Twitter accounts, information were gathered in the direct messages and shared tweets from the libraries. Thus, hypothesized that CCA Library social media accounts and library contents can significantly influence the promotion of academic library services among students $(\mathrm{H} 2)$;

The findings of Burrio [18] mentioned that the benefits of social media as a solid network tool include creating a bond among professionals for disseminating data. Affirmed by Mustafa [8] in his study that social media platforms are channels in answering users' inquiries and in providing immediate feedbacks on promotional initiatives. Thus, hypothesized that relative advantages of using social media in the library can significantly influence the promotion of academic library services among students (H3).

\section{MethodolOGY}

This study is a quantitative-based study which employed SmartPLS 3.0 version to predict the influence of social media platforms in promoting the academic library services of City College of Angeles. The proponents decided to use the quantitative research method over qualitative method for it does not require a longer time for the collection of data. In the study conducted by Rahman [21] explained that the quantitative method is more dominant in assessment research He also stated some of the weaknesses of qualitative method like for instance, smaller sample size and also it is time consuming. A structured survey questionnaire with 39 items was used as a research instrument. The instrument generated was based on previous related studies to achieve the objectives of this study. A five- point Likert scale was utilized to identify the use of social media platforms, the purpose of usage, and the relative advantages of using social media among the students. Likert Scale is one of the most primary and frequently used psychometric tools in education research. [22]. The survey questionnaire used was validated by three professors before they were randomly distributed to all the respondents, specifically among 3rd year and 4th year college students. A total number of one hundred seventy-four respondents from the City College of Angeles were given enough time to answer the questions.

\section{A. Analytical Tools}

Hair [23] stated that SmartPLS is a software application with ease of use and intuitive graphical user interface that has significant point of development in latent variable modeling. It has coherent ideas [24]; it is a study on SmartPLS [25]; it is an advantageous tool for management science to prepare, produce, and authenticate models.

\section{B. Construct Reliability}

The study used Cronbach's alpha as a measure of internal consistency and to test reliability technique. It is the average value of the reliability coefficients to be attained for all possible combinations of items when split into two half-tests
[26], [27].

\section{Convergent Validity}

Convergent Validity describes the Average Variance Extracted (AVE) of the selected values above 0.5 [22].

\section{Discriminant Validity}

Discriminant Analysis measures the amount of differences between overlying constructs [28]. Heterotrait-monotrait ratio (HTMT) criterion was adopted in this study. It is a method in evaluating discriminant validity, one of the key building blocks of model evaluation [29], [30].

\section{ANALYSIS AND RESUlTS}

Analysis and reports were based on the total number of 174 students from the City College of Angeles, Pampanga in the Philippines.

\section{A. Demographic Details}

Table I shows that the respondents were dominated by males with a total of $60.9 \%$, while the female respondents were just $39.1 \%$. There were $67.82 \%$ respondents coming from the $4^{\text {th }}$ year level, while $32.1 \%$ composed the respondents coming from the 3 rd year level.

TABLE I: DEMOGRAPHIC DETAILS
\begin{tabular}{|l|l|l|l|}
\hline Categories & Male & 106 & Percentage \\
\hline \multirow{2}{*}{ Gender } & Female & 68 & $60.9 \%$ \\
\hline \multirow{2}{*}{} & $3^{\text {rd }}$ & 174 & $39.1 \%$ \\
\hline \multirow{2}{*}{ Year level } & $4^{\text {th }}$ & 56 & \\
\hline \multicolumn{2}{|l|}{} & 118 & $32.18 \%$ \\
\hline Department & IEAS & 39 & $67.82 \%$ \\
\cline { 2 - 4 } & IBM & 52 & $22.41 \%$ \\
\cline { 2 - 4 } & ICSLIS & 83 & $29.89 \%$ \\
\hline
\end{tabular}

Table I illustrates the three different colleges of City College of Angeles included in the study: Institute of Education, Art and Sciences (IEAS) is" composed of $22.41 \%$ respondents; Institute of Business and Management with 29.89\%; and the Institute of Computing Studies and Library and Information Science (ICSLIS) with $47.70 \%$ respondents, respectively.

\section{B. Construct Reliability and Validity}

The reliability of this study was based on recommended composite and Cronbach's alpha value above 0.7 . Convergent validity for each construct was based on the 0.5 achieved value. Thus, constructs reliability and validity are reported in Table II.

TABLE II: CONSTRUCT RELIABILITY AND VALIDITY

\section{Construct Reliability and Validity}

\begin{tabular}{|c|c|c|c|c|c|}
\hline Matrix & Ho Cronbach's Alpha & th tho A & It Composite Reliability & \multicolumn{2}{|c|}{ Hoverage Variance Extracted (AVE) } \\
\hline & & Cronbach's Alpha & \multicolumn{2}{|c|}{ tho_A Composite Reliabil... } & Average Variance Extracte... \\
\hline CONTENTS & & 0.843 & 0.896 & 0.869 & 0.575 \\
\hline PURPOSE & & 0.782 & 0.794 & 0.857 & 0.668 \\
\hline RELATIVE_AD & AVVANTAGE & 0.843 & 0.835 & 0.871 & 0.534 \\
\hline SOCIAL_MED & & 0.737 & 0.783 & 0.846 & 0.649 \\
\hline
\end{tabular}




\section{Discriminant Validity}

Discriminant validity was achieved through heterotrait-monotrait ratio values as shown in Table III [31]. Internet Banking Adoption in Nigeria: A Literature Review. Computers (pp. 374-378) ACM].

TABLE III: DISCRIMINANT VALIDITY

\section{Discriminant Validity}

\begin{tabular}{|c|c|c|c|c|}
\hline \multirow[t]{2}{*}{ Fornell-Larcker Criterion } & Cross Loadings & \multicolumn{3}{|c|}{ Heterotrait-Monotrait Ratio (HTMT) } \\
\hline & CONTENTS & PURP... & RELATIVE_ADVANTAGE & SOCIAL_MEDIA \\
\hline \multicolumn{5}{|l|}{ CONTENTS } \\
\hline PURPOSE & 0.412 & & & \\
\hline RELATIVE_ADVANTAGE & 0.700 & 0.558 & & \\
\hline SOCIAL_MEDIA & 0.184 & 0.456 & 0.333 & \\
\hline
\end{tabular}

\section{Path Coefficients and Hypotheses Reports}

Path coefficients achieved were based on standard deviation, $t$-statistics, $p$-values, and extracted values. Hence, coefficients are illustrated in Table IV.

TABLE IV: PATH COEFFICIENTS

\begin{tabular}{|l|l|l|l|l|l|l|}
\hline \multicolumn{2}{|l|}{ Regression } & Sample & Dev & T.Statistics & P-Value \\
\hline Contents & $\rightarrow$ & $\begin{array}{l}\text { Social } \\
\text { media }\end{array}$ & 0.071 & 0.020 & 3.592 & 0.000 \\
\hline Purpose & $\rightarrow$ & $\begin{array}{l}\text { Social } \\
\text { media }\end{array}$ & 0.167 & 0.083 & 2.035 & 0.029 \\
\hline Relative & $\rightarrow$ & $\begin{array}{l}\text { Social } \\
\text { media }\end{array}$ & 0.584 & 0.089 & 6.528 & 0.000 \\
\hline
\end{tabular}

All the hypotheses were supported at value $<0.000$ except "purpose toward the use of social media" which is supported at $t$-statistics of 2.035 and $p$-value indicated as 0.029 . Furthermore, library content is supported at $t$-statistics of 3.592 and $p$-value of 0.000 . The relative advantage is supported at $t$-statistics of 6.528 and $p$-value of 0.000 . Thus, this study shows the bootstrapped model in Fig. 2

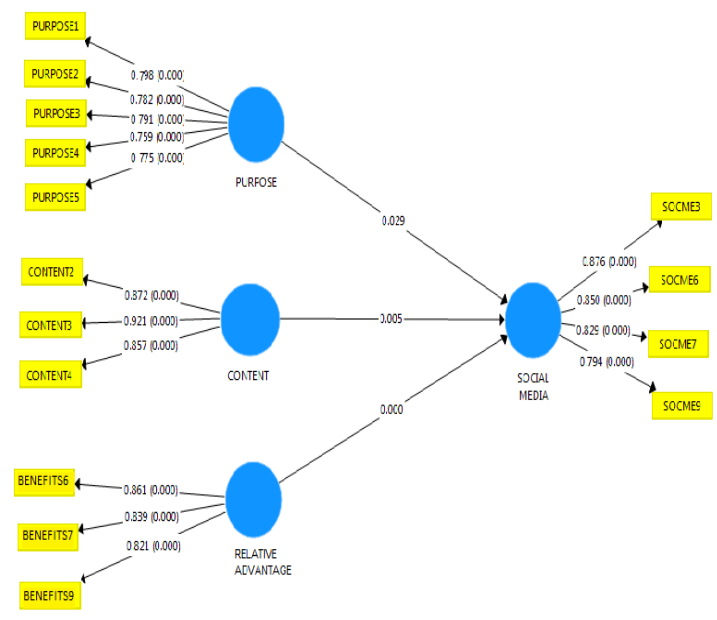

Fig. 2. Social media bootstrapping model.

Fig. 2 illustrates the factors in identifying the use of social media in promoting the academic library services among students at City College of Angeles, Pampanga, Philippines. Moreover, Algorithm property of SmartPLS ran to justify $\mathrm{R}$-square of $87 \%$ reported as the variance explanation of the structured model.

\section{Discussions AND CONCLUSION}

The framework of this study found related to technology acceptance model (TAM), perceived purpose, library social media accounts and library contents, and relative of advantage influencing social media adoption among College Students. The findings of the study presented the use of social media platforms in the promotion of the academic library services among the students at City College of Angeles. Furthermore, the types of social media platforms most used by the students, the library social media account contents, and the relative advantages of using social media at the libraries were taken into consideration. The results provided in the quantitative data were supported by structured interviews to validate the responses of the respondents coming from students at the 3rd year and 4th year level.

Further, results were paralleled with the findings from the study conducted by Howard [15]. It was emphasized that most of the students use social media platforms such as Facebook, Instagram, Twitter, and YouTube. It was also identified that based on the responses, users were interested in different types of library content except those related to business news. Results showed that YouTube is one of the most significant and used library resources to acquire new service information and knowledge. On the contrary, Library Content did not give the respondents much interest to utilize the resources; they were more motivated to use the latest and most popular social media sites. The results of the study enhanced the level of understanding on the social media usage and its significance in promoting the academic library services among the students at City College of Angeles. It is recommended that libraries must have a system of expanding quality services for its users. Better communication channels must be established further by using social media platforms to acquire updated and relevant knowledge and information.

\section{LiMITATION OF THE STUDY}

This study was mainly focused on the randomly selected bona fide students of the City College of Angeles specifically $3^{\text {rd }}$ year and $4^{\text {th }}$ year college students. The study also focused on the use of social media platforms particularly of Facebook, Twitter and Instagram in promoting the academic library services in the City College of Angeles, Angeles City, Pampanga, Philippines.

Another notable limitation, why this study cannot be generalized is due to the location of the study which was only conducted at City College of Angeles, Pampanga, Philippines. Furthermore, the numbers of participants may also consider as one of the limitation, in terms of total population of the region.

The period of the study may also consider as limitation due to short period of one year. 


\section{CONFLICT OF INTEREST}

The authors declare no conflict of interest

\section{AUTHORS CONTRIBUTIONS}

Mark Gil Superio and Dr. Richard G. Daenos contributed in the development of Instrument and provided assistant during data collection and help in proofreading and formatting the paper. Diana Tuliao, Eric Dungca and Princess Rona Gabriel assisted in data collection and literature and reference. Hazelle Ann Yalung write up and data entry and coding, and she is also serve as one of the main contributor of this study. Solomon Oluyinka, assisted in data entry and coding. Also development of framework, modification of the concepts. Solomon assisted in the area of data analysis and writing of this article. Solomon is the brain box of this study.

\section{ACKNOWLEDGMENT}

This study acknowledged the significant contributions and support of the City College of Angeles community in completing the study. Our deepest gratitude goes to our teacher-adviser, Dr. Solomon Oluyinka, for his magnetic influence and expertise to put the study into completion. Special appreciation goes to Dr. Anatalia N. Endozo of Angeles University Foundation for reviewing and formatting the study.

\section{REFERENCES}

[1] L. Booker and S. Bandyopadhyay, "How academic libraries can leverage social networking to popularize their services: An empirical study," Journal of the Indiana Academy of the Social Sciences, vol. 16, no. $2,2017$.

[2] S. A. Khuhro, A. Burio, K. Ngin, and D. Vasan, "MobiGuard: A mechanism for protecting and controlling user's personal data on android smartphones," Imperial Journal of Interdisciplinary Research (IJIR), vol. 3, no. 12, pp. 50-58, 2017.

[3] Ogbuiyi, B. A. Akporhonor, and F. N. Olise, "LIbrarians use of social media for promoting library and information resources and services in university libraries in South-South," 2015.

[4] B. K. Hiremath and Y. Kenchakkanavar, "Social networking sites in academic libraries: a review of the literature," E-library Science Research Journal, vol. 5, no. 6, pp. 1-6, 2016.

[5] S. V. R. M. Rani, "Influence of social networking sites on library and information centers," International Journal of Library \& Information Science, vol. 6, no. 1, 2017.

[6] Sh. Sharyna and H. Basri, "User engagement with social media implication on the library usage a case of selected public and academic libraries in Malaysia," Library Philosophy and Practices e-Journal, vol. 5 pp. 1-32, 2018.

[7] S. K. Chu and H. S. Du, "Social networking tools for academic libraries," Journal of Librarianship and Information Science, vol. 45 , no. $63,2013$.

[8] A. Mustafa et al., "Social media tools in academic library," International Journal of Computer Theory and Engineering, vol. 8, no. 3, 2016.

[9] P. Jain, "Application of social media in marketing library and information services: A global perspective," European Journal of Business Economics and Accountancy, vol. 1, no. 1, 2013.

[10] M. J. Jones and M. Harvey, "Library 2.0: The effectiveness of social media as a marketing tool for libraries in educational institutions," Journal of Librarianship and Information Science, vol. 51, no. 1, pp. 3-19, 2019.

[11] E. M. Eze, "Awareness and use of web 2.0 tools by LIS students at University of Nigeria, Nsukka, Enugu State, Nigeria," Library Philosophy \& Practice, 2016.

[12] K. Mahmood and J. Richardson, "Impact of Web 2.0 technologies on US academic libraries: A study of ARL," The Electronic Library, vol 31, no. 4, 2013.
[13] E. M. Chitumbo, "Social media tools for academic library services," International Journal of Humanities and Social Science Invention, vol. 4, no. 9, pp. 33-40, 2015.

[14] L. LeBlanc and K. Kim, "Web 2.0 and social media: Applications for academic libraries," Information Security and Computer Fraud, vol. 2, no. 2, pp. 28-32, 2014.

[15] H. Howard, S. Huber, L. Carter, and E. Moore, "Academic libraries on social media; finding the students and the information they want," Information Technology and Libraries, 2018.

[16] S. Palmer, "Characterizing university library use of social media: A case study of Twitter and Facebook from Australia," The Journal of Academic Librarianship, pp. 611-619, 2014.

[17] K. Hansen, G. Nowlan, and C. Winter, "Pinterest as a tool: Applications in academic libraries and higher education," Canadian Journal of Library and Information Practice and Research, vol. 7, no. $2,2012$.

[18] M. Burio et al., "Social media used for promoting the libraries and informatiom resources and services at University Lbrariesof Sindh province," presented at International Conference on Innovative Research and Development, 2018.

[19] O. A. Bakare et al., "Use of social media platforms to promte library services and profitable librarianship," International Journal of Scientific \& Zengineering Research, vol. 9, no. 7, 2018.

[20] A. M. Elkaseh, K. W. Wong, and C. C. Fung, "Perceived ease of use and perceived usefulness of social media for e-learning in Libyan higher education: A structural equation modeling analysis," International Journal of Information and Education Technology, vol. 6, no. 3, p. 192, 2016.

[21] M. S. Rahman, "The advantages and disadvantages of using qualitative and quantitative approachesand method language "testing and assessment" research: A literature review," Journal of Education and Learning, vol. 6, no. 1, pp. 102-112, 2017.

[22] D. V. Dyck et al., "IPAQ interview version: Convergent validity with accelerometers and comparison of physical activity and sedentary time levels with the self-administered version," pp. 776-786, 2015.

[23] J. Hair. (2019). Definition of SmartPLS 3. [Online]. Available: https://www.smartpls.com

[24] T. Sander and T. Lee, "SmartPLS for the human resources fild to evaluate a model," New Challenges of Economic and Business Development, 2014.

[25] S. Oluyinka and A. N. Endozo, "Barriers to e-learning in developing countries: A comparative study," Journal of Theoretical and Applied Information Technology, vol. 97, no. 9, 2019.

[26] J. Gliem and R. Gliem, "Calculating, interpreting and reporting Cronbach's Alpha reliability coefficient for Likert-Type Scales," in Proc. 2003 Midwest Research Conference in Adult, Continuing, and Community Education, pp. 82-88, 2003.

[27] S. Ayodele, A. Endozo, and M. E. Ogbari, "A study on factors hindering online learning acceptance in developing countries," in Proc. the 10th International Conference on Education Technology and Computers, pp. 254-258, 2018.

[28] A. Hami, M. R. Sami, and M. H. M. Sidek, "Discriminant validity assessment: Use for Fonll and Larcker critetion and HTMT criterion," Jornal Physic; Conference Series, 2017.

[29] S. A. Oluyinka, A. N. Endozo, and R. R. Calma, "Study on acceptance of internet banking," in Proc. the 10th International Conference on Education Technology and Computers, pp. 374-378, 2018.

[30] A. N. Endozo, "Structuring the quadratic effect of motivation towards mental tasks performance among university students," Journal of Theoretical and Applied Information Technology, vol. 97, no. 13, 2019.

[31] O. Solomon et al., "Internet banking adoption in Nigeria: A literature review," Computers, pp. 374-378, 2014.

Copyright $\odot 2020$ by the authors. This is an open access article distributed under the Creative Commons Attribution License which permits unrestricted use, distribution, and reproduction in any medium, provided the original work is properly cited (CC BY 4.0).

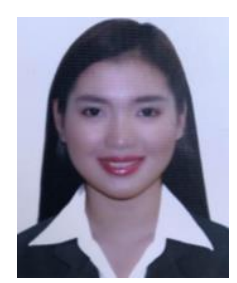

Hazelle Ann Yalung is currently taking up the bachelor of library and information science as a fourth year graduating student at the City College of Angeles in Pampanga, Philippines. She was included in the Dean's Honor List for five consecutive semesters starting second semester of academic year 2016 up to second semester of academic year 2019. She is an active student and at the same time a hardworking 
employee. She currently works in Jollibee, fast food chain in Angeles Pampanga, Philippines as a service crew for 4 years. She was also an active member in school organizations and participates in various school events.

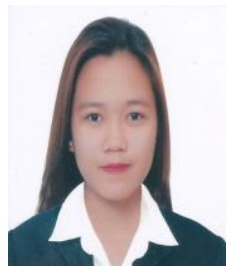

Diana L. Tuliao is a graduating student of the bachelor of library and information science at the City College of Angeles, Pampanga, Philippines. She participated in various seminars including a recent seminar entitled "Awesome Writing Endeavors: A Utilization of Productivity tools in Research" at the City College of Angeles, Pampanga, Philippines. She also attended the PLAI-CelRLC LIS Forum with title "The Innovative Librarian in the Era of Interconnectivity and Inclusivity" at Bulacan State University, Bulacan, Philippines.

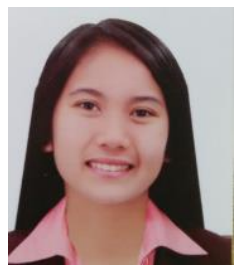

Princess Rona M. Gabriel is a graduating student of the bachelor of library and information science at the City College of Angeles, Philippines and at the same time she also works as a sale assistant in Nepo Mall, Angeles City. She participated in a seminar entitled "BLIS Region 3: Moving up Together in Research" at the City College of Angeles. She also attended a recent seminar program in PLAI-CeLRLC Leaders' Summit held at Bulacan State University in Bulacan, Philippines with the title "Brown Bag Session on Partnership, Networking, andLinkages (PNL): an Explanatory Meeting with Library Leaders of Schools, Colleges, and Universities in the Region".

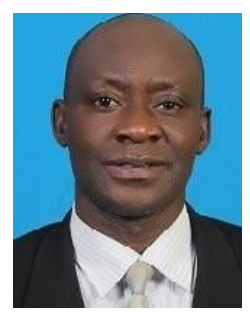

Solomon Oluyinka is currently an instructor at Baliuag University College of Business Administration and Accountancy and has a part-time affiliation with the City College of Angeles. He holds a doctoral degree in technology management major in marketing at Universiti Teknologi Malaysia. He has over 8 years of teaching experience and 4 years industry experience in marketing management and human resource management. Solomon has won several awards such as graduate on time award, Publication Award, Most Active Postgraduate Student, Best Paper Award, Most Promising Leadership Award and other academic and professional awards and recognitions to name a few. His recent paper presentation "The study on the acceptance of internet banking" at ICETC 2018 in Tokyo, Japan obtained the Best Paper Award. Being a professional teacher, editor, consultant and researcher, Solomon is actively involved in trainings related to research methods and statistical analysis. He is one of the reviewers of Journal of Applied Structural Equation Modeling (JASEM) and ESN International Journal of Economics and Social Science. He also served as a lecturer at several universities and research bodies in Malaysia. As an active researcher, Solomon has published 19 articles in various distinguished scholarly journals (ABS, SCOPUS and ISI Web of Science Indexed) and presented at several conferences locally and abroad. His main research area covers Technology Acceptance, Management Practices, Talent Management, Educational Management and Advance Quantitative Research Methods. Solomon has previously facilitated versions of more than 10 workshops on Basic and Advanced Quantitative Research Methods, SPSS, SmartPLS 3.0 and AMOS for graduate and postgraduate students.

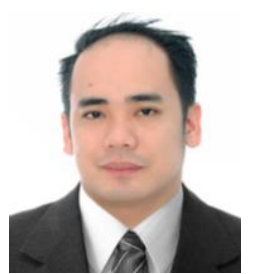

Mark Gil Q. Superio is currently the dean of the Institute of Computing Studies and Library Information Science of the City College of Angeles City. He is pursuing his studies at Angeles University Foundation, taking up Doctor in Information Technology. He completed his Master of Information Technology at Systems Plus College Foundation and his bachelor's degree in computer science at Holy Angel University. His major of specialization is in the field of Cisco Networking and has been in the Cisco Networking Academy for eight years.

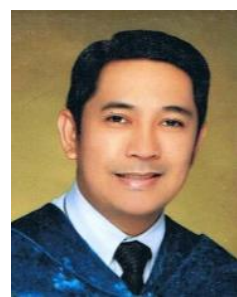

Richard G. Daenos is a multiawarded educator and researcher with a special interest in cultural and heritage tourism and teacher education. He completed his doctor of philosophy major in educational management, master of arts in special education and master of arts in education major in English and bachelor of secondary education major in English at Angeles University Foundation. In recognition of his academic background and expertise, he was conferred of the following : Doctor Fellow of Royal Institute of Tourism, Singapore (2019), Doctor of Fellow of Royal Institute of Education, Singapore (2019), International Visiting Professorial Fellow of the Royal Institution, Singapore, (2018) Fellow of the Asia Pacific Institute for Events Management, United Kingdom, (2018), Senior Fellow of the Royal Institute of Educator and Research, Singapore (2017) and as a Fellow in Business Education by the Philippine Academy of Professionals in Business Education, Philippines (2017). He was a recipient of the following scholarships and grants: a) Cultural Partnership Initiative 10th Anniversary and International Symposium held in 2015 and Cultural Exchange and Residency Fellowship in 2012 sponsored by the UNESCO - KISS and Ministry of Culture, Sports and Tourism of South Korea, b) Group Study Exchange - Culture and Vocation held in 2010 and sponsored by the Rotary International held in Denmark and Lithuania, c) Capacity Building Course in Community Development within a University Context and Gender and Human Rights Issues held in 2003 and sponsored by the Canadian International Development Agency held in Canada. He has presented papers in reputable international conferences and fora in countries like Indonesia (2019), Malaysia (2018), South Korea (2015), Denmark and Lithuania (2012), United States of America (2009 and 2008), South Africa and United Kingdom (2007) among others. He has become a part of the teaching force of leading universities and academic institutions in Asia and Philippines, including Southeast Asian Ministers of Education Organization Innotech (SEAMEO Innotech), De la Salle University, University of Sto. Tomas and Angeles University Foundation. Dr. Daenos was appointed as the Tourism Officer of Angeles City in 2014 - 2016. He was elected as Secretary of the National Committee on Monuments and Sites of the National Commission for Culture and the Arts in 2016 and still holds the same post to date. He likewise serves as a member of the Board of the International Council on Monuments and Sites (ICOMOS) - Philippines. At present, he is the President of the City College of Angeles. He also serves the regional and national organizations of the Association of Local Colleges and universities where he is assigned of key leadership positions. 